\title{
28. PALEOMAGNETISM OF SEDIMENT CORES FROM DEEP SEA DRILLING PROJECT LEG 58, PHILIPPINE SEA
}

\author{
Hajimu Kinoshita, Department of Earth Sciences, Chiba University, Yayoi-cho, Chiba, Japan
}

\begin{abstract}
Nine hundred and twenty-five minicores from DSDP Sites 442 through $\mathbf{4 4 6}$ were studied. After alternating-field demagnetization of natural remanent magnetization (NRM), the absolute values of inclination of the stable n.r.m. of sediment cores showed a systematic change with age. During the last $42 \mathrm{~m}$.y., the mean absolute values of inclination changed by about $20^{\circ}$, indicating a northerly drift of the sampled region of about $2000 \mathrm{~km}$ with a velocity of at least $5 \mathrm{~cm} / \mathrm{yr}$.
\end{abstract}

\section{INTRODUCTION}

Recent paleomagnetism studies of oceanic crust are mostly based upon (1) measurements of total magnetic field over certain seamounts (Harrison et al., 1975; Franchateau et al., 1970; Vacquier and Uyeda, 1967), (2) phase-angle analyses of the magnetic-lineation patterns (Heirtzler et al., 1968; Larson and Laurie, 1975; Louden, 1977; Opdyke and Todd, 1977; Shouten and McCarmy, 1972; Vine, 1968), (3) measurements of n.r.m. of volcanic rocks from oceanic islands or atolls (Gromme and Vine, 1972; Kalashnikov, 1961; Kawai et al., 1969, 1971), and (4) measurements of n.r.m. inclination of deep-sea sediments (Hammond et al., 1974; Kalashnikov, 1961; Kawai et al., 1969, 1971; Lancelot and Ewing, 1973; Hammond et al., 1974; Louden, 1977; Peierce, 1976; Sasajima et al, 1968; Sclater and Cox, 1970). Although the methods of measurement, technique of analyses, reliability of data, objectives, and sampled materials (including their ages) are vastly different in these studies, results mostly show that both the Pacific and the Atlantic ocean basins and adjacent regions have been moving northward in relation to the present geomagnetic pole during the last $100 \mathrm{~m}$.y. This inference has been corroborated by many other lines of evidence related to island chains and sediments of the equatorial regions (Clague and Jarrard, 1973; Fitch, 1972; Jackson et al., 1972; McElhinny, 1973; Mimstek et al., 1974; Morgan, 1971; Vine and Hess, 1970). DSDP Leg 58 has made possible the study of a large number of soft and consolidated sediment samples from the northern Philippine Sea plate, which cover a period from the Holocene back 42 m.y. to the middle Eocene. The results of the present work are in agreement with other paleomagnetism results for oceanic materials.

\section{PALEOMAGNETISM MEASUREMENTS ON SEDIMENT SAMPLES}

Five sites were drilled on DSDP Leg 58. Sediments obtained at Sites 442 through 444 were not well consolidated; hence, the paleomagnetism samples were mechanically disturbed. At Site 445 a sub-bottom depth of about 900 meters was reached, and the cores were fairly well consolidated below 120 meters. At Site 446, a number of consolidated-sediment cores were recovered below a sub-bottom depth of 50 meters.

NRM was measured with a flux-gate magnetometer. All the specimens were demagnetized with an alternating field (AF) along three mutually perpendicular axes. A maximum peak field strength of 150 oe was determined rather arbitrarily through our experiences on the stability of deep-sea-sediment remanent magnetization. Samples with stable NRM were selected on the basis of the following criteria: (1) The median destructive field is larger than 150 oe; (2) the directional change of NRM through 150-oe AF demagnetization does not exceed $10^{\circ}$ along a great circle; and (3) the Koenigsberger ratio, $Q_{n}=\mathrm{NRM} / x H$ (where $x$ is the initial magnetic susceptibility of the specimen, and $H$ is the total force of the geomagnetic field of the sampled site is larger than 10 .

As an example of the measurements, the absolute values of stable NRM for Sites 445 and 446 are plotted versus sub-bottom depth in Figure 1. In this plot, NRM of lesser stability (those with $Q_{n}$ between 5 and 10) are included. Intensity of the virgin NRM is averaged over every 10 meters. It is interesting to note that the NRM intensity jumps to high values at a sub-bottom depth around 650 meters. This jump might reflect an abrupt change in volcanic activity.

A number of minicores were dried and pulverized in a mortar and magnetically separated. $J_{s}-T$ measurements were carried out in a vacuum of $10^{-4} \mathrm{~mm} \mathrm{Hg}$, over a temperature range of 0 to $600^{\circ} \mathrm{C}$. An example of the $J_{s}-T$ curve is presented in Figure 2.

$\mathrm{X}$-ray-diffraction and fluorescence measurements on these magnetic separates revealed that the main magnetic mineral has cubic symmetry, with a lattice parameter between 8.35 and $8.40 \AA$. This mineral was found to be titanomagnetite with a low titanium content.

\section{COMPACTION EFFECT}

There is a critical argument whether the consolidation of sediments significantly alters the inclination 

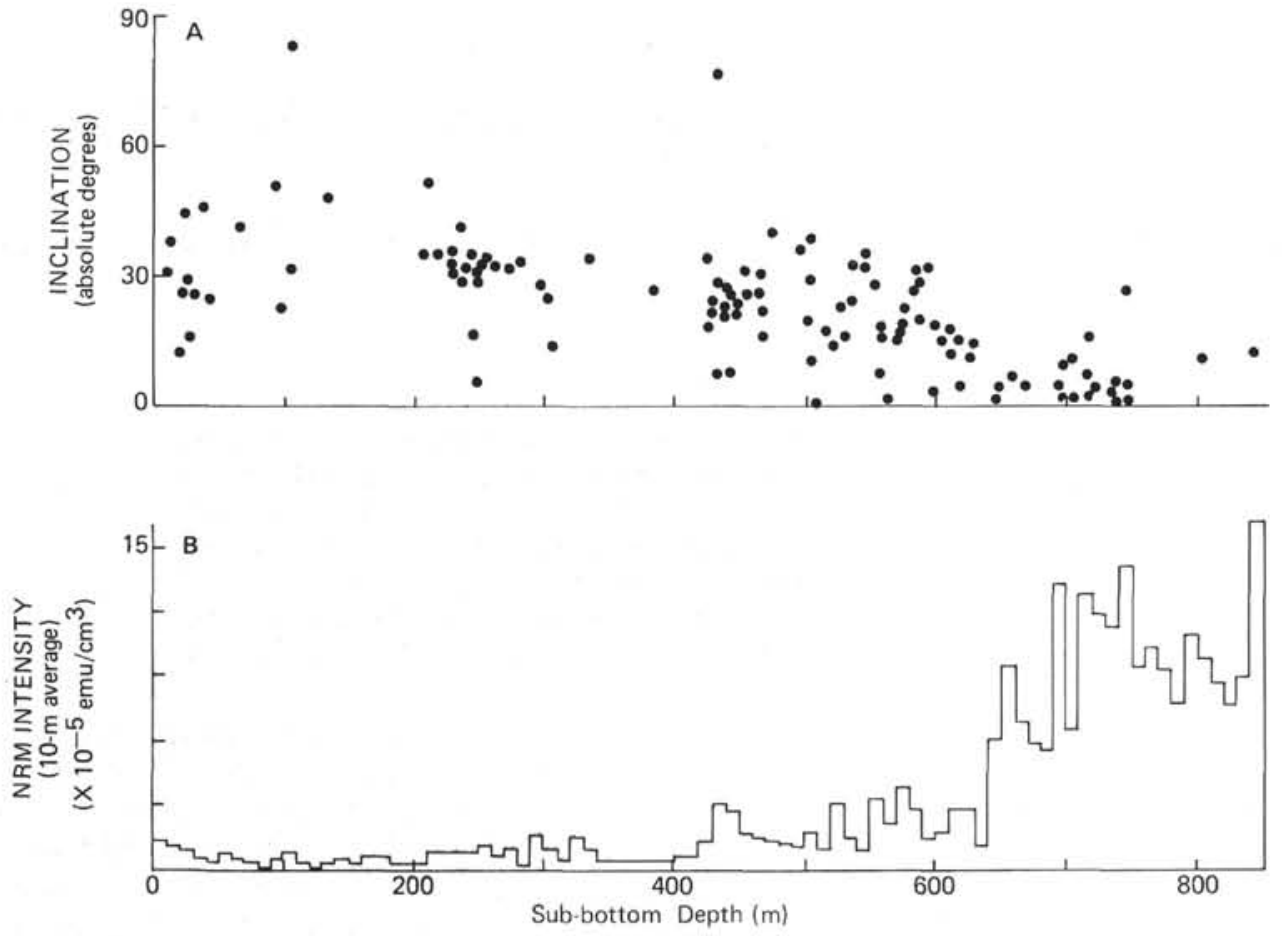

Figure 1. A. Absolute values of NRM inclination plotted against sub-bottom depth.

B. Ten-meter averages of NRM intensity for Site 445 .

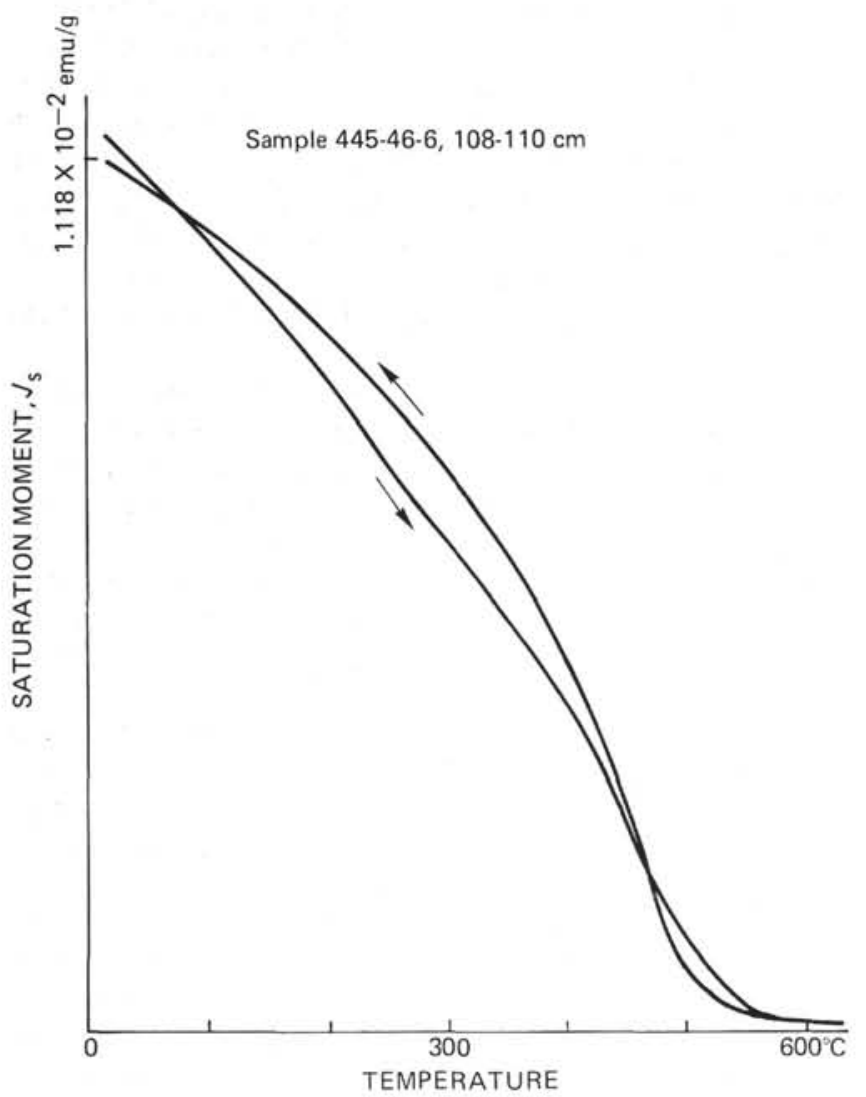

Figure 2. Representative $\mathrm{J}_{\mathrm{s}} \mathrm{T}$ curves for a magnetic separate, obtained in a magnetic field of $3 \mathrm{koe}$, in vacuo. values of n.r.m. from that of the geomagnetic field at the time of sedimentation. A detailed discussion of this problem was first given by King and Rees (1966), who, however, did not definitely state whether there is a definitive correlation between inclination of NRM and consolidation (compaction).

Recently Kodama and Cox (1978) showed that there is no substantial change in the direction of artificial remanent magnetization after a certain amount of plastic deformation of sedimentary samples.

This seems to indicate that there is no positive correlation between compaction of sediments and inclination values of NRM. The plot in Figure 3, where the absolute values of inclination of stable AF-demagnetized NRM are represented as a function of density of the cored sediments, does not show any definitive correlation.

This leads the author to infer that the absolute values of stable NRM inclination represent actual mean values of the inclination of the geomagnetic field of the site at the time of formation of sediment (deposition and consolidation of the sediment occurred virtually at the same time, with respect to changes in geomagnetic inclination).

\section{CHANGE OF NRM INCLINATION WITH GEOLOGIC TIME AND ITS IMPLICATIONS}

A statistical treatment was applied to the absolute values of NRM inclination. Cores are grouped according to their geologic age: Pleistocene, Pliocene, Miocene, Oligocene, and Eocene. Samples from Sites 442 


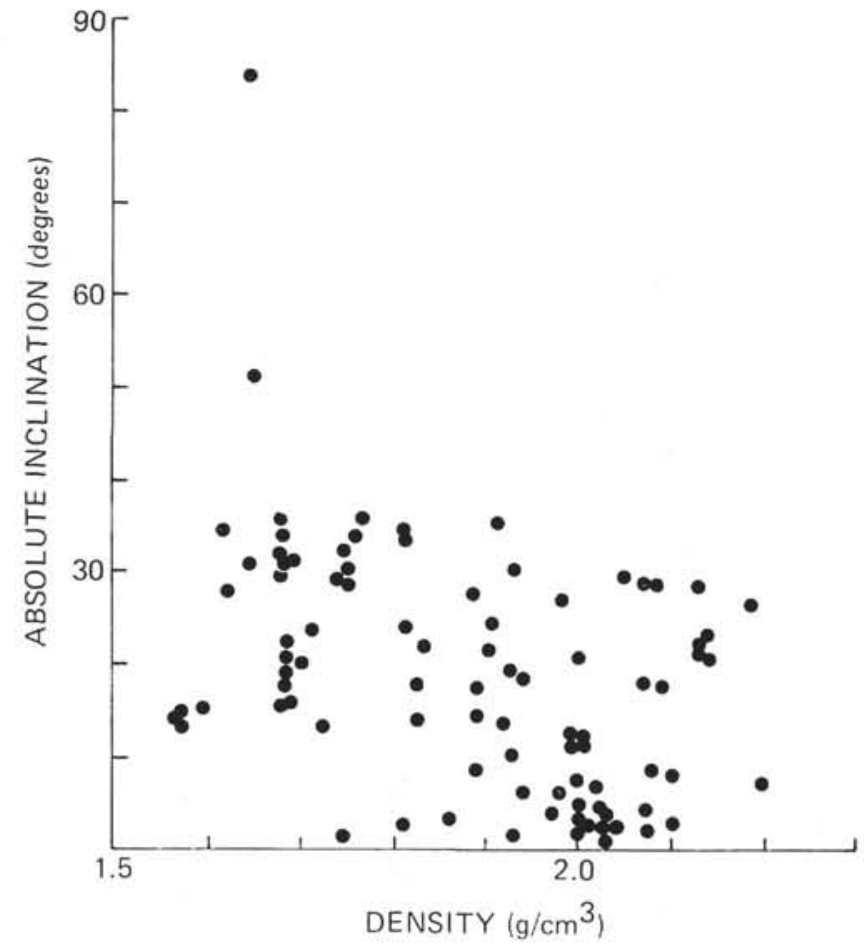

Figure 3. Relation between absolute values of NRM inclination and sample density. Samples are from Site 445 .

through 444 (population 1) and samples from Sites 445 and 446 (population 2) are treated separately, because they are from two different basins; the latitudes for these two groups are clustered around two slightly different values.

The mean and the standard deviation of the n.r.m. inclination for each epoch are first calculated for the populations. Then the paleolatitudes of drilling sites are calculated from the mean values, and corresponding upper and lower limits are given by the standard deviation. It is assumed that the Earth's magnetic moment has been a geocentric dipole and that the dipole moment remained parallel to the Earth's rotational axis on the average for the last $50 \mathrm{~m} . \mathrm{y}$.

Paleolatitudes and probable deviations from the mean are plotted in Figure 4. The point for site-survey piston-core samples represents the inclination of n.r.m. averaged over 166 specimens obtained from the topmost 3.3 meters of the piston cores (corresponding to 0-0.5 m.y.; Tonouchi, pers. comm).

Three aspects of the data in Figure 4 are noteworthy.

First, the paleolatitude for Pleistocene sediments is smaller by about $10^{\circ}$ than the present value. This can be explained in one of two ways: (1) the inclination of the Pleistocene geomagnetic field of the region was lower than the present mean value as a result of geomagnetic dipole wobbling, or (2) the NRM inclination of sediments is systematically distorted by drilling and sample handling. The first argument, however, can be ruled out, because the secular variation of geomagnetic inclination in southwest Japan varies around $45^{\circ}$, with an

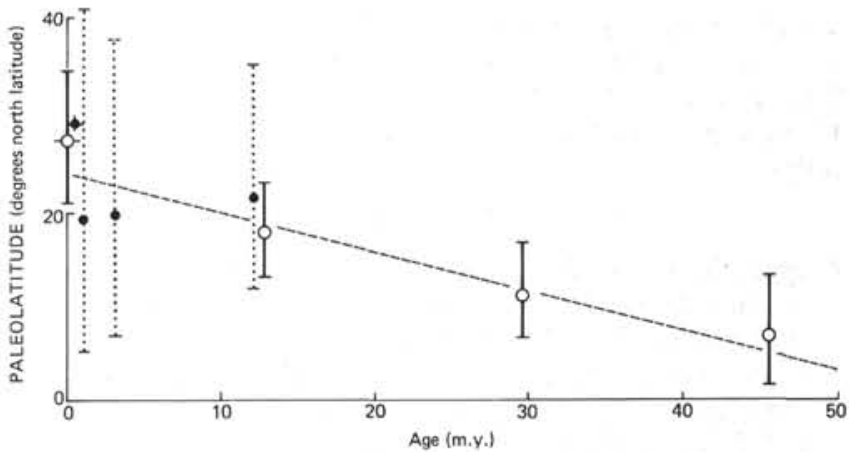

Figure 4. Paleolatitudes calculated from mean values of NRM inclination as a function of age. Error bars are based on the standard deviation of NRM inclination. Open circles are plots for the Daito region (Sites 445 and 446), and solid circles are plots for the Shikoku Basin (Sites 442 through 444). The two points just at 0 m.y. represent the paleolatitude calculated from NRM data for site-survey piston-core samples from the Daito Ridge (open circle) and the present latitude deduced from the inclination $\left(47.9^{\circ}\right)$ of the present geomagnetic field at Site 442 (solid circle). The dashed line is an approximation of the least-squares fit, based solely upon Daito region NRM data. Unequal lengths of error bars on each side of means result from projection of the standard deviation of NRM inclination directly to the latitudinal value.

amplitude about $15^{\circ}$ for the time represented by archaeological materials (Watanabe, 1958; Hirooka, 1971 and 1972), and the present value is precisely on a trough of the secular-variation curve. This kind of secular variation is observed worldwide, and it is probably caused by a superposition of dipole wobbling and drift of the geomagnetic non-dipole field (Cox and Doell, 1964). According to the relation between the standard deviation of the inclination and the latitude given by these authors, the inclination for Site 445 in the Pleistocene should be limited approximately to $43 \pm 8^{\circ}$. This value agrees with the paleomagnetism results for piston cores from this region $\left(45 \pm 8^{\circ}\right.$; Tonouchi, pers. comm.).

Second, as shown by the difference between the present latitude of the Daito region and its paleolatitude during the Eocene, the Daito region must have been located closer to the equator and must have drifted northward about $2000 \mathrm{~km}$ since the Eocene. Assuming a constant rate of motion and due-north drift, the drift rate is at least $5 \mathrm{~cm} / \mathrm{yr}$.

Third, although it is not clear whether the Daito region was in the northern or southern hemisphere during the Eocene, the region seems to have crossed the equator about $45 \mathrm{Ma}$. A similar argument is presented by Louden (1977) in relation to a paleomagnetism study of cored sediments from the western Philippine Sea basin.

\section{ACKNOWLEDGMENTS}

The author is greatly indebted to Dr. T. Furuta and Mr. Tonouchi, University of Tokyo, for their assistance in magnet- 
ic and mineralogical analyses of sediment samples and for the offer of a set of unpublished data on deep-sea-sediment n.r.m. Thanks are due to Prof. K. Kobayashi and Prof. S. Uyeda, University of Tokyo, for their critical reading of the manuscript.

\section{REFERENCES}

Clague, D. A., and Jarrard, R. D., 1973. Tertiary Pacific plate motion deduced from the Hawaiian-Emperor chain. Geol. Soc. Am. Bull., 84, 1135-1154.

Cox, A., and Doell, R., 1964. Long period variations of the geomagnetic field. Bull. Seismol. Soc. Am., 54, 2243-2270.

Fitch, T. J., 1972. Plate convergence, transcurrent faults, and internal deformation adjacent southeast Asia and the western Pacific. J. Geophys. Res., 77, 4432-4460.

Franchateau, J., Harrison, C. G. A., Sclater, J. G., and Richards, M. L., 1970. Magnetization of Pacific seamounts; a preliminary polar curve for the northeastern Pacific. $J$. Geophys. Res., 75, 2035-2061.

Gromme, S., and Vine, F. J., 1972. Paleomagnetism of Midway atoll lavas and northward movement of the Pacific plate. Earth Planet. Sci. Lett., 17, 159-168.

Hammond, S. R., Theyer, F., and Sutton, G. H., 1974. Paleomagnetic evidence of northward movement of the Pacific plate in deep-sea cores from the Central Pacific Basin. Earth Planet. Sci. Lett., 22, 22-28.

Harrison, C. G. A., Jarrard, R. D., Vacquier, V., and Larson, R. L., 1975. Paleomagnetism of Cretaceous Pacific seamounts. Geophys. J. Roy. Astr. Soc., 42, 859-882.

Heirtzler, J. R., Dickson, G. O., Herron, E. M., Pitman, W. C., and LePichon, X., 1968. Marine magnetic anomalies, geomagnetic reversals, and motions of the ocean floor and continents. J. Geophys. Res., 73, 2119-2136.

Hirooka, K., 1971. Archaeomagnetic study for the past 2,000 years in Southwest Japan. Memoir Faculty. Sci. Kyoto Univ., Ser. Geol. Mineral., 38, 167-207.

1972. On the geomagnetic secular variation in southwestern Japan. Kaiyo Kagaku, 51-59 [in Japanese].

Jackson, E. D., Silver, E. A., and Dalrymple G. B., 1972. Hawaiian-Emperor chain and its relation to Cenozoic circum-Pacific tectonics. Geol. Soc. Am. Bull., 83, 601-608.

Kalashnikov, A. G., 1961. History of the geomagnetic field. Izv. Akad. Nauk, Geofiz. Ser., 9, 1243-1279.

Kawai, N., Hirooka, K., and Nakajima, T., 1969. Paleomagnetic and potassium-argon age information supporting Cretaceous-Tertiary hypothetical bending of the main island, Japan. Palaeogeogr. Palaeoclimatol. Palaeoecol., 6, 277-282.

Kawai, N., Nakajima, T., and Hirooka, K., 1971. The evolution of the island arc of Japan and the formation of gran- ites in the circum-Pacific belt. J. Geomagnet. Geoelec. 23, 267-293.

King, R. F., and Rees A. I., 1966. Detrital magnetism in sediments; an examination of some theoretical models. $J$. Geophys. Res., 71, 561-571.

Kodama, K., and Cox, A., 1978. The effect of a constant volume deformation on the magnetization of the artificial sediments. Earth Planet. Sci. Lett., 38, 436-442.

Lancelot, Y., and Ewing, J., 1973. Evidence of Pacific plate movement from the Cenozoic and Mesozoic sedimentary record. Trans. Am. Geophys. Union, 54, 331.

Larson, R. L., and Lowrie, W., 1975. Paleomagnetic evidence for motion of the Pacific plate from Leg 32 basalts and magnetic anomalies. In Larson, R. L., Moberly R., et al., Init. Repts. DSDP, 32: Washington (U. S. Govt. Printing Office), pp. 571-578.

Louden, K. E., 1977. Paleomagnetism of DSDP sediments, phase shifting of magnetic anomalies, and the rotation of the west Philippine basin. J. Geophys. Res., 82, 2989-3002.

McElhinny, M. W., 1973. Mantle plumes, paleomagnetism and polar wandering. Nature, 241, 523-524.

Minster, J. B., Jordan, T. H., Molnar, P., and Haines, E. 1974. Numerical modelling of instantaneous plate tectonics. Geophys. J. Roy. Astr. Soc., 36, 541-576.

Morgan, W. J., 1971. Convection plumes in the lower mantle. Nature, 230, 42-43.

Opdyke, N. D., and Todd, A., 1977. The extension of the magnetic time scale in sediments of the central Pacific ocean. Earth Planet. Sci. Lett., 22, 300-306.

Peierce, J. W., 1976. Assessing the reliability of DSDP paleolatitudes. J. Geophys. Res., 81, 4173-4187.

Sasajima, S., Nishida, J., and Shimada, M., 1968. Paleomagnetic evidence of a drift of the Japanese main island during the Paleogene period. Earth Planet. Sci. Lett., 5, 135-141.

Shouten, H., and McCarmy, K., 1972. Filtering marine magnetic anomalies. J. Geophys. Res., 77, 7089-7099.

Sclater, J., and Cox A., 1970. Paleolatitudes from JOIDES deep-sea sediment cores. Nature, 226, 934-935.

Vacquier, V., and Uyeda, S., 1967. Paleomagnetism of nine seamounts in the western Pacific and of three volcanoes in Japan. Bull. Earthquake Res. Inst. Tokyo Univ., 45, 815-848.

Vine, F. J., 1968. Paleomagnetic evidence for the northward movement of the north Pacific basin during the past 100 m.y. Trans. Am. Geophys. Union, 49, 156.

Vine, F. J., and Hess, H. H., 1970. Sea floor spreading. In Maxwell, A. E. (Ed.), The Sea (Vol. 4, Part II): New York (Wiley-Interscience), pp. 587-622.

Watanabe, N., 1958. Secular variation in the direction of geomagnetism as the standard scale for geomagnetochronology in Japan. Nature, 182, 383-384. 